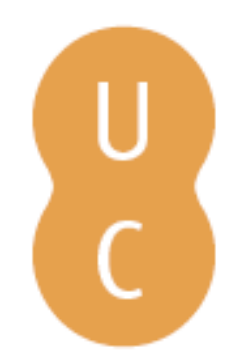

\title{
pompalina
}

\section{A organização da rede de cuidados de Saúde Infantil e Juvenil em Portugal}

Autor(es): $\quad$ Peixoto, José Carlos

Publicado por: Imprensa da Universidade de Coimbra

URL

persistente: URI:http://hdl.handle.net/10316.2/43103

DOI: $\quad$ DOl:https://doi.org/10.14195/978-989-26-1300-0_2

Accessed : $\quad$ 26-Apr-2023 13:54:15

A navegação consulta e descarregamento dos títulos inseridos nas Bibliotecas Digitais UC Digitalis, UC Pombalina e UC Impactum, pressupõem a aceitação plena e sem reservas dos Termos e Condições de Uso destas Bibliotecas Digitais, disponíveis em https://digitalis.uc.pt/pt-pt/termos.

Conforme exposto nos referidos Termos e Condições de Uso, o descarregamento de títulos de acesso restrito requer uma licença válida de autorização devendo o utilizador aceder ao(s) documento(s) a partir de um endereço de IP da instituição detentora da supramencionada licença.

Ao utilizador é apenas permitido o descarregamento para uso pessoal, pelo que o emprego do(s) título(s) descarregado(s) para outro fim, designadamente comercial, carece de autorização do respetivo autor ou editor da obra.

Na medida em que todas as obras da UC Digitalis se encontram protegidas pelo Código do Direito de Autor e Direitos Conexos e demais legislação aplicável, toda a cópia, parcial ou total, deste documento, nos casos em que é legalmente admitida, deverá conter ou fazer-se acompanhar por este aviso.

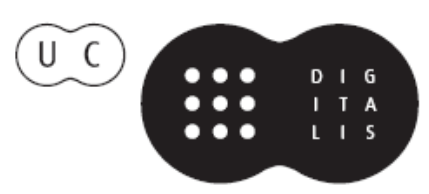


Capítulo 2.

A organização da rede

de cuidados de Saúde Infantil

e Juvenil em Portugal

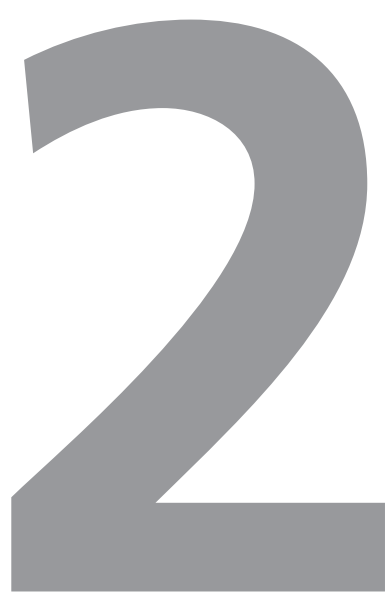

\section{José Carlos Peixoto}




\subsection{CONTEXTO}

A maioria dos países com padrões de desenvolvimento humano semelhantes ao nosso, meIhorou consideravelmente as taxas de mortalidade infantil (TMI) a partir dos anos 70, figura 1.A melhoria das condições de vida contribuiu para esta evolução favorável generalizada. Contudo, em Portugal, outros fatores justificaram a queda significativa da TMI verificada a partir dos anos 90. Na verdade, Portugal foi o país que mais reduziu a TMI evoluindo da pior taxa da Europa para passar a integrar, de forma sustentada, o grupo dos países com as TMI mais baixas do mundo, figura 2. Esta queda deve-se à diminuição progressiva das taxas de mortalidade neonatal e neonatal precoce, exatamente as que dependem menos das condições socioeconómicas e muito mais da organização e desempenho dos cuidados de saúde.

\subsection{DESCRIÇÃO DO TEMA}

Há 25 anos, em Portugal, uma conjugação feliz de vários fatores, que passamos a descrever para memória futura, esteve na base deste sucesso, nomeadamente: i) a vontade política em investir na estruturação da Saúde Materna e Infantil (SMI) face à situação precária de Portugal no ranking dos indicadores da SMI, relativamente aos parceiros da União Europeia (UE); ii) o envolvimento na solução de um conjunto de líderes visionários que já conheciam a realidade do país, sentiam o problema e sabiam as soluções; iii) a nomeação em 1989 da primeira Comissão Nacional da Saúde Materna e Infantil (CNSMI); iv) a visão estratégica correta e a conceção competente do Programa Nacional da Saúde Materna e Infantil (PNSMI); e v) a comunicação e o envolvimento dos profissionais como executores deste projeto.

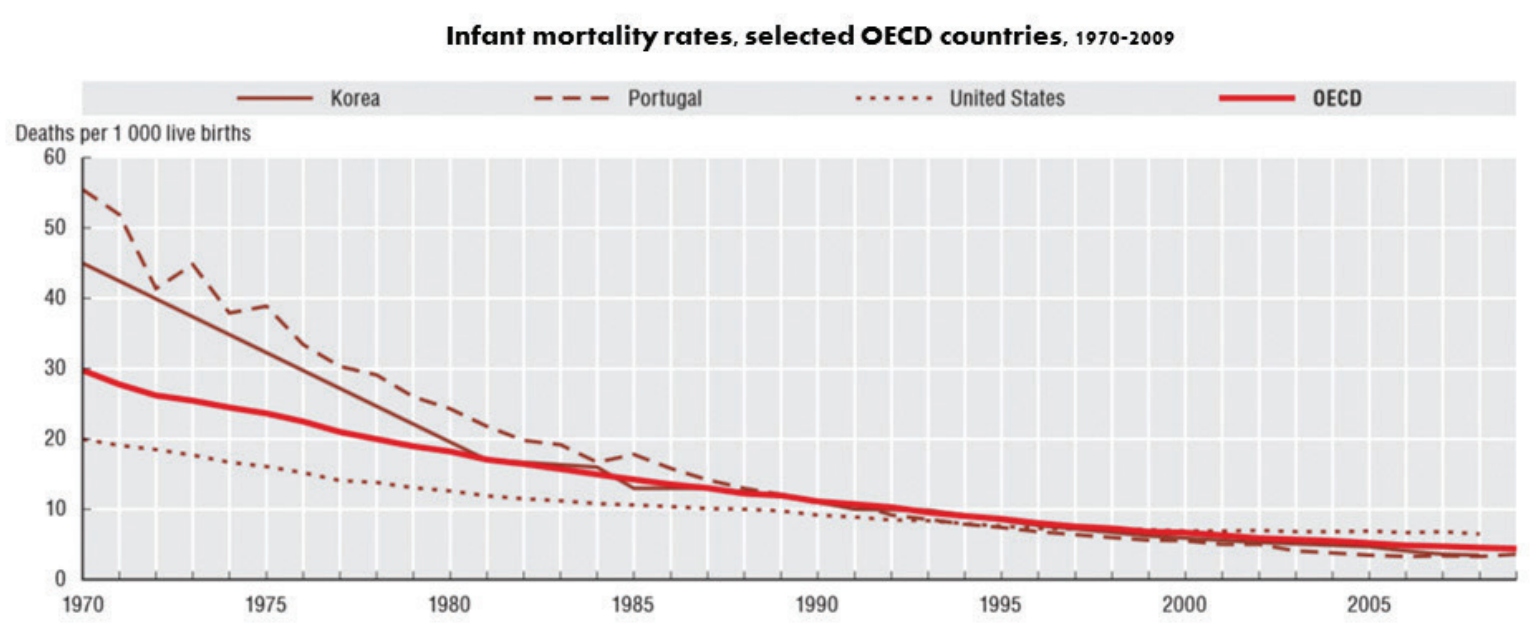

Source: OECD Health Data 2011.

HEALTH AT A GLANCE 2011: OECD INDICATORS @ OECD 2011

Figura 1. Evolução da taxa da mortalidade infantil em Portugal e países da OCDE (1988 -2009). 


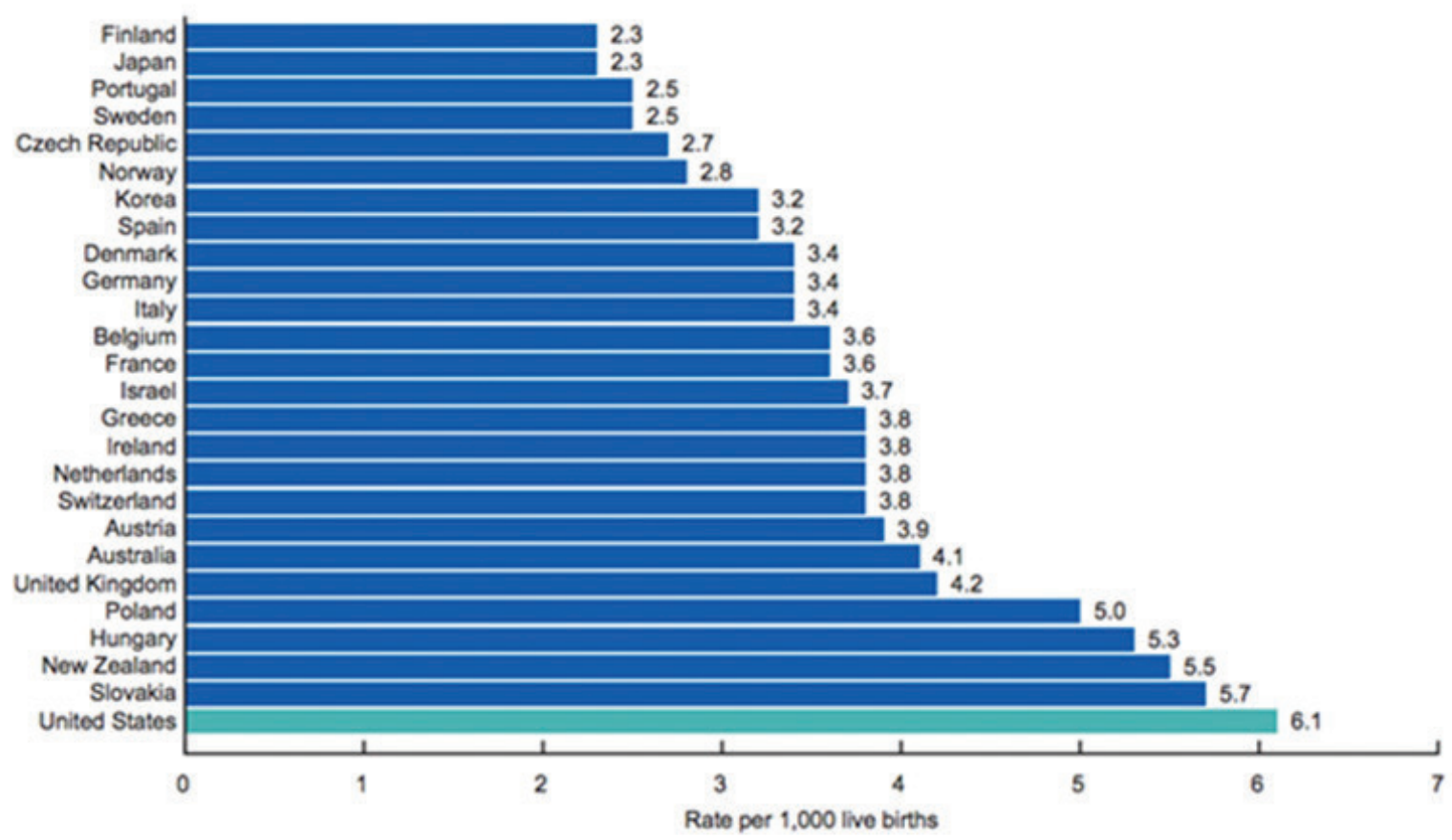

NOTES: Canada's 2010 data were not walable from the Organisation for Economic Co-cperaton and Development (OECO) at the ime of manuscript preparation. The 2009 intart montaly rate for Canada was 49 . if the 2010 data for Canada had been avallable, the U.S. ranking may have changed. Deafhs at all pestatonal ages are inoluded, but courteres may vary in completeress of

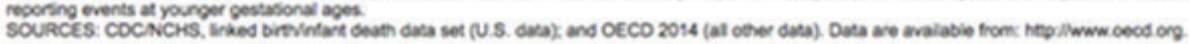

Figura 2. Comparação internacional das taxas de mortalidade infantil.

A autonomia concedida à CNSMI para implementar o PNSMI e a capacidade de assumir compromissos com uma estratégia de curto médio e longo prazo, garantiram a continuidade das bases do sucesso e a história demonstrou que os investimentos nesta área foram imprescindíveis e altamente recompensados. Portugal transformou-se num caso modelo de assistência na área da SMI e os profissionais e utentes passaram a aceitar e a defender o PNSMI como um Património Nacional.

Transcreve-se o testemunho do Professor Henrique Carmona da Mota sobre esse momento histórico (figura 3).

\subsubsection{Visão estratégica do PNSMI}

Os circuitos de vigilância da grávida, do recém-nascido (RN), da criança e adolescente devem ser assegurados com universalidade e equidade no acesso e na assistência como esquematizado nas figuras 4 e 5 .

A segurança no parto e a qualidade do nascimento têm que ser asseguradas e garantidas a todos os portugueses.

Os bons cuidados exigidos ao nascer obrigam a antecipação de uma boa vigilância da grávida e definição prévia do local de nascimento. 
Conissio mactonuL de sadise Matekn E INFantL Docunentos DE TRuaniso

cuibubos de saúse MTERAA E NEO-LATAL गано 198

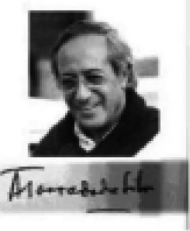

" Com base em trabalhos pioneiros (Grupo de trabalho para a melhoria dos cuidados em perinatalogia (DGS 1980), Comissão Nacional de Avaliação da situação da grávida e do recém-nascido - Albino Aroso, Octávio Cunha, Pereira Leite... et al.1985) constituiu-se um grupo nacional de peritos de Obstetrícia e Pediatria neonatal (Torrado da Silva, Albino Aroso, Octávio Cunha, Pereira Leite, Martins Palminha, Luís Carvalho, Dória Nóbrega, Purificação Araújo, Vicente Souto) coordenado pelo secretário de Estado Baptista Pereira (do ministério de Leonor Beleza), redigiu o Relatório sobre Cuidados de saúde materna e neo-natal em 1989 (anexo) que deu origem ao Programa Nacional de Saúde Materna e Infantil."

In : Mota HC-Efemérides da Pediatria portuguesa 2. Acta Pediatr Port 2009:40(6):288-94

Figura 3. Testemunho da origem do Programa Nacional de Saúde Materna e Infantil.

A segurança no parto exige equipas perinatais competentes com disponibilidade permanente e equipamento adequado, em todos os locais onde se nasce.

A comunicação e cooperação entre os vários profissionais envolvidos e a complementaridade entre as instituições são imprescindíveis para garantir a assistência universal e continuidade de cuidados, figura 4.

A articulação dos cuidados hospitalares entre si, entre estes e os cuidados primários e a integração/inclusão do setor privado, superiormente regulamentada é obrigatória para garantir uma assistência eficiente, figura 5.

Os recursos devem ser rentabilizados, adequados e adaptados às necessidades assistenciais.
Os cuidados de vigilância exigidos, devem ser garantidos na proximidade, para facilitar o acesso às populações e os cuidados que exigem experiência, segurança, estrutura e equipamentos diferenciados devem ser concentrados.

A monitorização de indicadores, a avaliação e a formação contínuas e a circulação da informação são fundamentais para garantir a atualização das normas de orientação clínica, o cumprimento das boas práticas e uma melhoria contínua da qualidade.

O envolvimento e participação dos profissionais e das sociedades científicas são imprescindíveis. A coordenação deve ser competente, técnica, cooperante, motivada e contínua. 


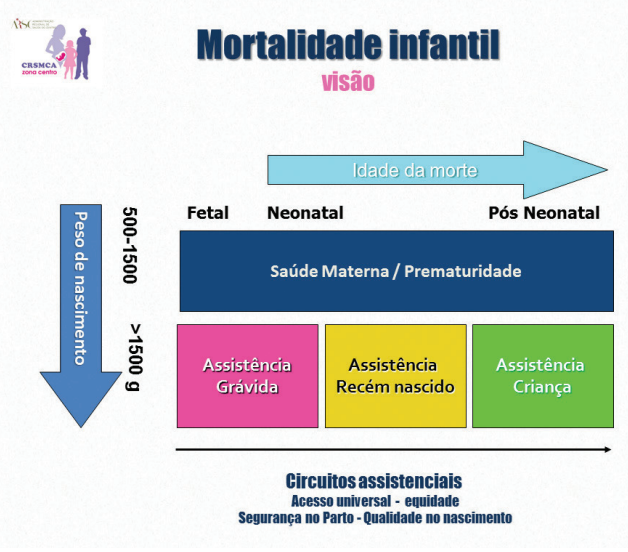

Figura 4. Intervenções necessárias para consolidar a baixa sustentada da Mortalidade Infantil.

\subsubsection{Implementação do PNSMI}

Os Circuitos Assistenciais para a vigilância da Grávida, RN e Criança, figura 5 foram implementados garantindo equidade e facilidade no acesso e na assistência a nível nacional. Foi possível, graças ao sistema de vigilância partilhada, à cooperação multidisciplinar e complementaridade interinstitucional. A vigilância de primeira linha ficou assegurada nos Cuidados de Saúde Primários pelos Médicos de medicina geral e familiar e a referenciação quando necessária passou a ser garantida nas consultas de referência dos hospitais cumprindo os protocolos de referência interinstitucionais entretanto desenvolvidos e implementados pelas Unidades Coordenadoras Funcionais (UCF).

A Notícia de Nascimento implementada a nível nacional, foi um instrumento importante para promover a identificação, o registo e a

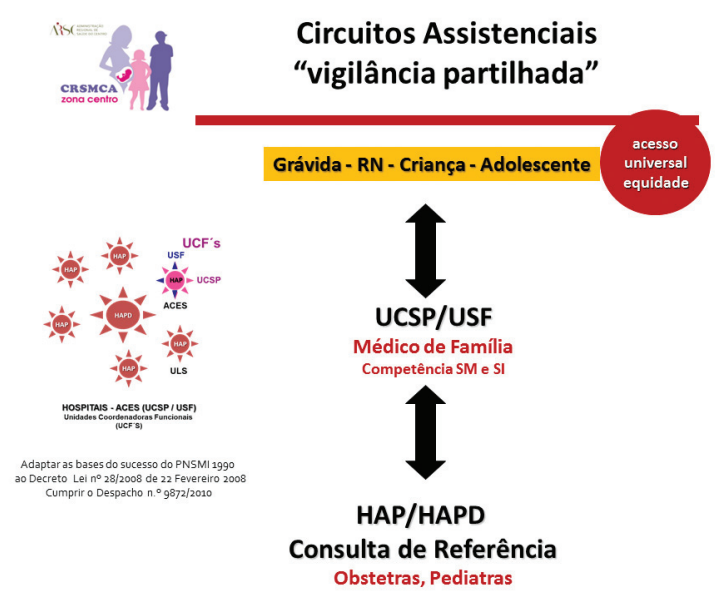

Figura 5. Organização dos Circuitos Assistenciais.

sinalização das situações de risco social para os cuidados primários e os registos aproveitados para avaliar as necessidades ainda não satisfeitas, o resultado da vigilância da gravidez, da qualidade do parto e do nascimento.

Após a alta do RN a continuidade de cuidados é garantida nos cuidados primários, nas respetivas Unidades de Saúde, para cumprir o Programa Nacional de Saúde Infantil e Juvenil (PNSIJ) recentemente atualizado (2013). As consultas de referência nos Serviços de Pediatria, as Equipas de Intervenção Precoce (ELI) integradas no Sistema Nacional de Intervenção Precoce (SNIPI), os Núcleos de Apoio às Crianças e Jovens em Risco (NACJR), o rastreio de doenças hereditárias do metabolismo, o cumprimento do Programa Nacional de Vacinação e a articulação com os estabelecimentos de ensino cumprindo os programas de Saúde escolar complementam esta intervenção. 
A segurança no parto e a qualidade no nascimento a nível nacional foram garantidos com o encerramento de mais de 150 locais onde se nascia sem as condições mínimas necessárias e com a reorganização e requalificação dos Serviços de Obstetrícia e Maternidades. Implementou-se: a formação a adequação e a distribuição de recursos humanos, (enfermeiras, obstetras, pediatras com subespecialidade em neonatologia - neonatologistas e anestesistas); a melhoria das instalações e a distribuição racional adequada dos equipamentos, com definição de "equipas perinatais tipo" para os serviços de urgência, que passaram a contar com a presença física permanente de um obstetra, de um pediatra e de um anestesista, de forma a garantir a assistência clínica adequada a todos os partos 365 dias por ano e 24 horas por dia; a viabilização de polos de reanimação e unidades de cuidados intermédios em todos os hospitais; e a organização de unidades de cuidados intensivos neonatais nos Hospitais de Apoio Perinatal Diferenciado (HAPD).

\section{Os casos de grande risco obstétrico e} neonatal passaram a ser concentrados nos HAPD graças ao transporte neonatal medicalizado interinstitucional e à promoção do transporte in uteru, com antecipação do melhor local para o nascimento. A adesão e o envolvimento dos profissionais e sociedades científicas na execução do PNSMI foram imprescindíveis para a concretização destes objetivos. Graças a estas orientações, é possível concentrar actualmente o nascimento nos HAPD de mais de $90 \%$ dos RN com idade de gestação inferior a 32 semanas e aumentar para mais de 90\% a sobrevida deste grupo. Estas intervenções foram decisivas para reduzir ainda mais a TMI já que este pequeno grupo que corresponde a menos de $1 \%$ dos RN representa mais de $60 \%$ da mortalidade neonatal.

As Redes de Referenciação foram estruturadas para satisfazer simultaneamente as necessidades de vigilância na proximidade e concentrar as situações de risco para obter melhores resultados com menores custos. Estabeleceram-se as articulações entre os Cuidados de Saúde Primários e os Hospitais e estes entre si para a referenciação a áreas diferenciadas, figura 6; foram definidas as competências dos cuidados de saúde primários e dos cuidados de saúde hospitalares; foram definidos critérios para classificar os hospitais em Hospitais de Apoio Perinatal (HAP) e Hospitais de Apoio Perinatal Diferenciado (HAPD), articulados em redes com distribuição geográfica homogénea a nível nacional. O Sistema de Transporte Neonatal medicalizado interinstitucional, iniciado em 1986, foi alargado a todo o País a partir de 1989 e em 1994 passou a ser rentabilizado para o transporte pediátrico, atualmente efetuado até aos 18 anos.

\section{As Unidades Coordenadoras Funcionais}

(UCF) foram criadas um ano depois do início do PNSMI, para consolidar as redes assistenciais, e manter a articulação funcional entre os diferentes níveis de cuidados de saúde. São estruturas originais, constituídas por equipas multidisciplinares, integrando profissionais dos hospitais (serviços de obstetrícia e pediatria) e das respectivas Administrações Regionais de Saúde (ARS) com responsabilidades na saúde materna e infantil. Passaram a garantir: a coordenação; a comunicação e cooperação entre os especialistas hospitalares e os médicos de medicina geral e familiar; a elaboração dos protocolos de referência 
interinstitucionais em cada rede de referência; a circulação da informação; a divulgação e correta utilização do Boletim de Saúde da Grávida e do BSIJ; a divulgação, atualização e cumprimento das Normas de Orientação Clínica (NOC). São ainda responsáveis por monitorizar alguns indicadores recomendados pela CNSMI para avaliar as necessidades assistenciais locais, programar ações de formação, implementar programas de intervenção tais como, a auditoria multidisciplinar dos óbitos, das asfixias perinatais, das malformações, identificação e orientação das famílias com risco social, análise das vigilâncias inadequadas da gravidez, das referenciações e da grande prematuridade.

O reconhecimento da importância das UCF para dar coesão e continuidade à assistência na área da saúde materna e neonatal justificou o alargamento deste modelo organizativo aos circuitos assistenciais da criança e do adolescente.

\section{Constrangimentos e soluções}

A crise económica e a desejável necessidade de luta contra o desperdício precipitaram a necessidade de reformas na Saúde. A partir do ano 2000 o aparecimento de novos hospitais com novos modelos de gestão (SA, EPE, PPP), desinseridos das redes de referência, com autonomia administrativa e de gestão, nem sempre com supervisão central, não preveniram e em alguns casos até precipitaram a dispersão da assistência pediátrica e perinatal diferenciada.

A aposta na liberdade de concorrência, comprometeu os princípios da rentabilização de recursos, dificultou os processos de referenciação, começaram a ser postos em causa a equidade e a universalidade dos circuitos assistenciais e agravou substancialmente a relação custo-efetividade.
A última requalificação dos Serviços de Urgência perinatal operada em 2006, com o encerramento de blocos de parto que tinham na proximidade alternativas com melhor qualidade, atenuou esta tendência, permitiu rentabilizar os recursos existentes e garantir as "equipas perinatais tipo", uniformes em todo o País.

Numa altura de envolvimento coletivo no combate legítimo ao desperdício e obrigados a poupar, devemos afirmar que a assistência materna e infantil preconizada no PNSMI sempre foi das áreas com melhor relação custo-efetividade.

Este facto, creio que involuntariamente, não foi contemplado na recente e promissora reforma dos cuidados de saúde primários. Não se aproveitou este modelo para as soluções. Comprometeram-se as relações profissionais e interinstitucionais e o suporte legal das UCF.

O desaproveitamento do papel coordenador, mobilizador e consultor ao mais alto nível da CNSMCA, estrutura competente aceite e reconhecida pelos profissionais, não permitiu integrar as ações necessárias para acautelar o PNSMI na nova reforma, nem interferir nos indicadores e processos de contratualização em curso, nomeadamente para o cumprimento das funções das UCF.

As Comissões Regionais da Saúde da Mulher Criança e Adolescente (CRSMCA) representantes locais da CNSMCA, nos locais onde continuaram a ser reconhecidas pelos profissionais e pelas Administrações Regionais de Saúde (ARS), de quem dependem, mantiveram as relações profissionais e interinstitucionais, práticas históricas instituídas geradoras de muitos ganhos em saúde, garantindo a continuidade do trabalho das UCF.

A continuidade da CRSMCA da ARS do Centro beneficiando do reconhecimento e 


\section{zona centro \\ MANTERAS REDES DE REFERÊNCIAe UNIDADES COORDENADORAS FUNCIONAIS Materno-Infantil}

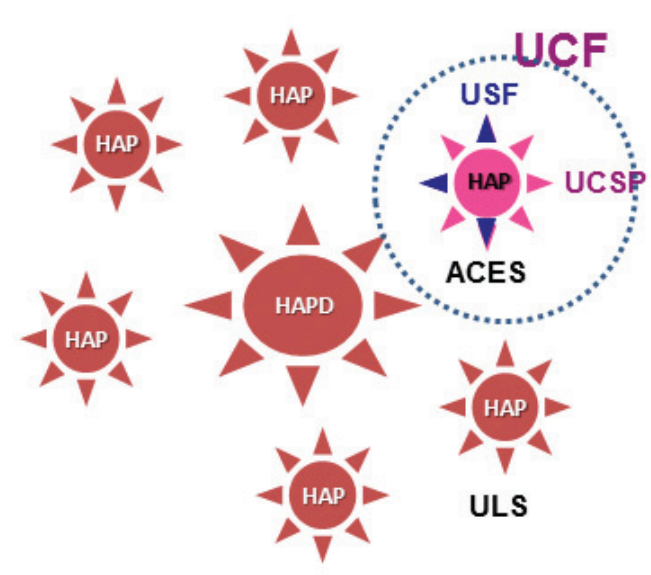

HOSPITAIS - ACES (UCSP / USF) Unidades Coordenadoras Funcionais (UCF'S)

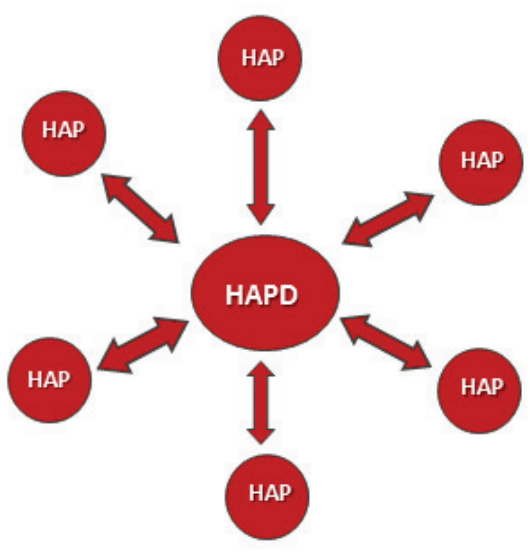

UCF INTER-HOSPITALARES

"HAPD" Hospital de Apoio Perinatal Diferenciado

"HAP" Hospital de Apoio Perinatal

Rentabilizar as Áreas Diferenciadas

Adaptar as bases do sucesso do PNSMI 1990 ao Decreto Lei $n^{\circ} 28 / 2008$ de 22 Fevereiro 2008 Cumprir o Despacho n. ${ }^{\circ} 9872 / 2010$

Figura 6. Redes de Referenciação e UCF.

autonomia concedidas pelos sucessivos conseIhos de administração da ARS, permitiu consolidar a Regionalização de Cuidados Perinatais e Pediátricos na Região Centro, figuras 6, 7, modelo invejável, difícil de implementar e consolidar, recomendado pelas sociedades científicas por ser o mais eficiente, evitando a dispersão dos serviços mais diferenciados.

A ação continuada das Comissões Regionais permitiu a elaboração do Despacho 9872/2010 que defende e permite dar continuidade ao
PNSMI, potenciando-o sem colidir com as virtudes da nova reforma. Com base neste Despacho foi possível "reativar" as UCF, repor-lhes o suporte legal, adaptá-las aos novos modelos de gestão, manter a interface entre os cuidados de saúde primários e os hospitalares, consolidar as relações inter-hospitalares e a referenciação para as áreas diferenciadas. Pela primeira vez foram constituídas as UCF inter-hospitalares tanto na vertente materna e neonatal como na vertente pediátrica e adolescente figuras 7 e 8 . 


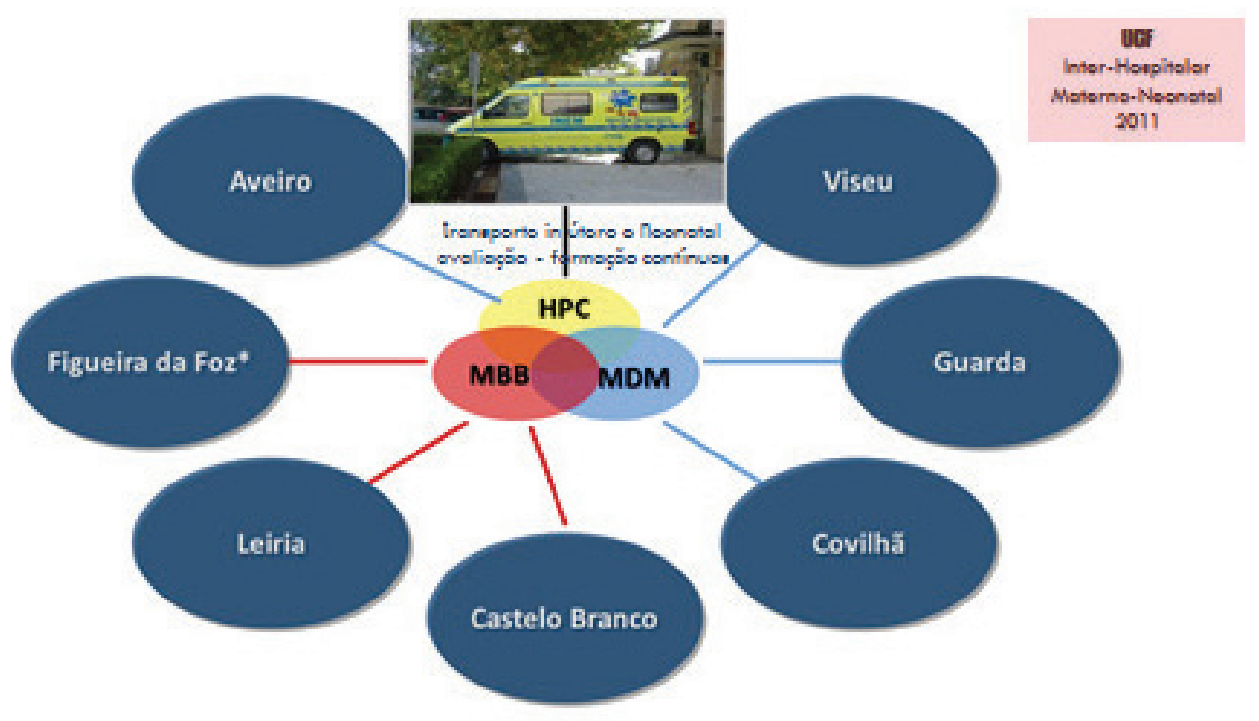

Goordenação - Gomunicação - Gontinuidade - Gooperoģão- Gomplenentaridade - Gompetência

Figura 7. Regionalização dos Cuidados Perinatais da Região Centro.

As "novas" UCF estão adaptadas à atual organização dos Cuidados de saúde primários sendo a estrutura de eleição para atenuar e corrigir as iniquidades em saúde detetadas em Portugal e referidas no relatório da OCDE em 2015.

A revisão do PNSIJ e a informatização do BSIJ e da Notícia de Nascimento e a prometida informatização do Boletim de Saúde da Grávida são instrumentos fundamentais para avaliar e dar coesão a esta assistência.

Os indicadores de contratualização para os cuidados da saúde primários e hospitalares atualmente em curso, orientados preferencialmente para a avaliação da produção, devem ser adaptados ao acesso e qualidade assistencial dos circuitos assistenciais e deverão incluir a avaliação dos resultados da qualidade dos cuidados de saúde prestados e garantir as funções das UCF.
Reconhecer o PNSMI como um património nacional, é uma obrigação de todos os profissionais de saúde que devem continuar a ser os seus advogados, e os seus executores e promover a sua integração nos Planos de ação dos Diretores de Serviço, dos Presidentes dos Conselhos Clínicos, dos responsáveis das Sociedades Cientificas e das Ordens profissionais.

\footnotetext{
PS: Se não assumirmos este Dever de Cidadania, se abdicarmos da gestão clínica, se nos deixarmos conduzir por uma gestão exclusivamente economicista, inconscientemente seremos induzidos a praticar uma medicina baseada em indicadores de produção, desviando-nos da essência da nossa profissão e talvez sejamos obrigados a reescrever esta história começando por "era uma vez". José Carlos Cabral Peixoto.
} 


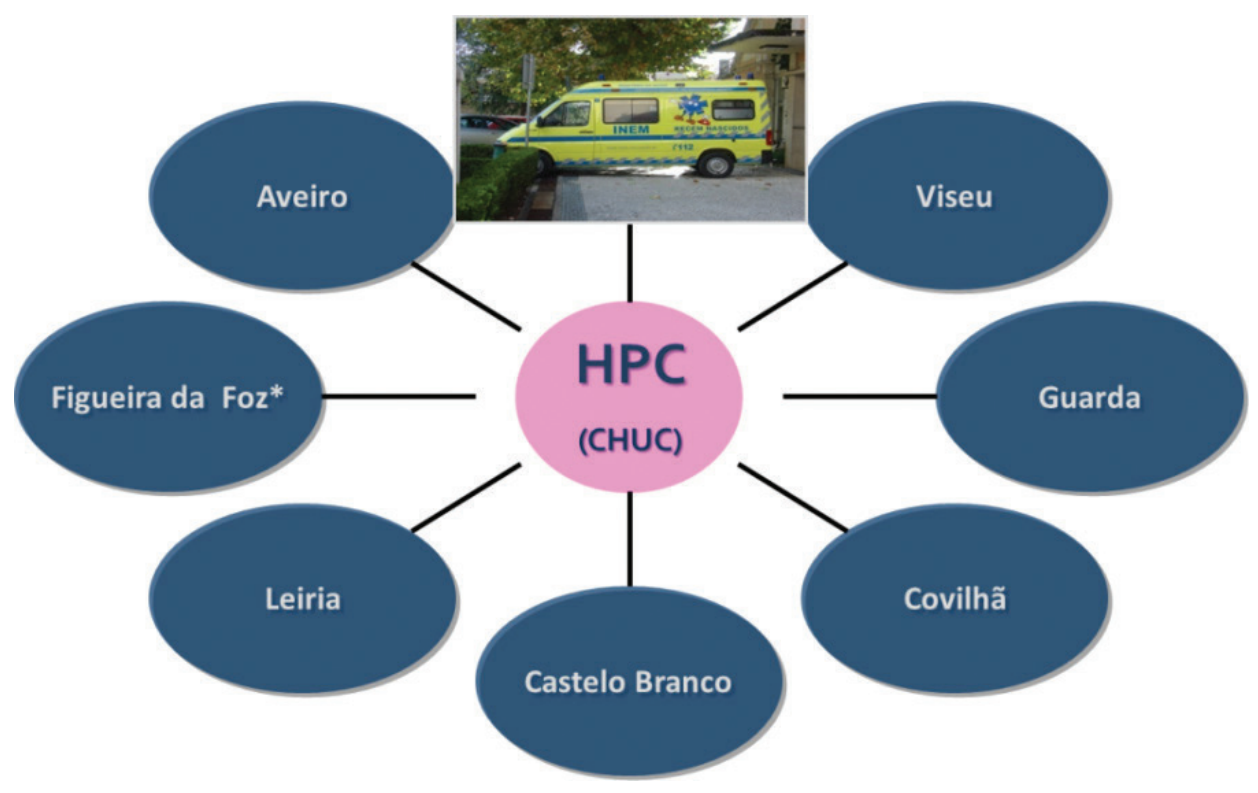

Figura 8. Regionalização dos Cuidados Pediátricos e Adolescentes da Região Centro.

\section{Leitura complementar}

Xavier Barreto e José Pedro Correia (coordenadores) Octávio Cunha, Alice Matos, José Peixoto, José Cunha Machado, Odete Alves Nina Sousa Santos. Fundação Francisco Manuel dos Santos, Julho de 2014. A mortalidade infantil em Portugal: evolução dos indicadores e factores associados entre 1988 e 2008. Disponível em:http://www.ffms.pt/estudo/14/evolucao-da-mortalidade-infantil

Despacho n. ${ }^{\circ}$ 9872/2010, 11 junho, Reorganização das Unidades Coordenadoras Funcionais e da Assistência Materna e Infantil. Ministra da Saúde Dra. Ana Jorge.

Portugal. Ministério da Saúde. Missão para os Cuidados de Saúde Primários. Linhas de Acão prioritárias para o desenvolvimento dos cuidados de saúde primários. Lisboa: Missão para os Cuidados de Saúde Primários. Ministério da Saúde, 2006.
PORTUGAL. Direcção-Geral da Saúde. Divisão de Saúde Materna, Infantil e dos Adolescentes Saúde MaternoInfantil: Rede de Referenciação Materno-Infantil. - Lisboa: Direcção-Geral da Saúde, 2001.

Grupo do Registo Nacional do Muito Baixo Peso. Seccão de Neonatologia da Sociedade Portuguesa de Pediatria. Registo Nacional dos Recém-Nascidos de Muito Baixo Peso. Rede de Investigação Neonatal Nacional. Acta Pediatr Port 1999;30:485-91.

Peixoto, J. C., Guimarães, H., Machado, M.C., Martins, V., Mimoso, G., Neto, M.T., et al. (Ed.). (2002). Nascer prematuro em Portugal - estudo multicêntrico nacional 1996 2000. PRÉMIO BIAL DE MEDICINA CLÍNICA 2002 Porto: Fundação Bial. 2010, disponível em: www.lusoneonatologia.net/usr/files/download/d5be427979a647e615755a1d04f4fa13.pdf 